\title{
Range extension of Brathinus satoi in China (Coleoptera, Staphylinidae)
}

\author{
Liang Tang', Li-Zhen Li' \\ I Department of Biology, Shanghai Normal University, 100 Guilin Road, 1st Educational Building 323 \\ Room, Shanghai, 200234 P. R. China \\ Corresponding author: Liang Tang (monkey_zzz1980@163.com)
}

Academic editor: M. Ivie | Received 5 June 2013 | Accepted 14 October 2013 | Published 22 October 2013

Citation: Tang L, Li L-Z (2013) Range extension of Brathinus satoi in China (Coleoptera, Staphylinidae). ZooKeys 344: 49-54. doi: 10.3897/zookeys.344.5740

\begin{abstract}
Brathinus satoi Kishimoto \& Shimada, 2003 is recorded from Longwangshan Nature Reserve, Zhejiang, China. Some diagnostic characters of the species are discussed based on more specimens, and some biological notes are made on the species.
\end{abstract}

\section{Keywords}

Coleoptera, Staphylinidae, Brathinus satoi, China

\section{Introduction}

Brathinus LeConte is a genus belonging to the Omaliinae. Bearing very long elytra covering most abdominal segments, adults of Brathinus are pretty bizarre, though their larvae (Thayer 1985) are rather typical Anthophagini. The adults could be misidentified as members of the Anthicidae or Staphylinidae: Scydmaeninae at first glance. In fact, Brathinus was originally described as a scydmaenid (LeConte 1852), later placed by LeConte (1861) in its own subfamily of Silphidae (sensu latissimo!), where it was when Lewis (1886) described the first Asian species, and treated as the family Brathinidae by Arnett (1963). Crowson (1955) first placed it in Omaliinae (or at any rate gave no earlier citation) and Hammond (1971) and Thayer (1985) provided more details and justification for that placement. 
Presently, six species of the genus have been described: B. californicus Hubbard, 1894, B. nitidus LeConte, 1852 and B. varicornis LeConte, 1852 from North America, B. oculatus Lewis, 1886 and B. shikokuensis Watanabe \& Sato, 1981 from Japan and B. sato $i$ Kishimoto \& Shimada, 2003 from China. The last species is the only species known from China, and was described from a single male specimen collected from Sichuan. More specimens of $B$. satoi were collected after many years of field work in Longwamgshan Nature Reserve of Zhejiang Province, which is more than 1000 kilometers from its type locality. Thus, some complementary comments on diagnostic characters and biological notes of the species can be provided.

\section{Material and methods}

For examination of the male genitalia, the last three abdominal segments were detached from the body after softening in hot water. The aedeagi, together with other dissected pieces, were mounted in Euparal (Chroma Gesellschaft Schmidt, Koengen, Germany) on plastic slides. Photos of sexual characters were taken with a Canon G7 camera attached to an Olympus SZX 16 stereoscope; habitus photos were taken with a Canon macro photo lens MP-E $65 \mathrm{~mm}$ attached to a Canon EOS40D camera. All the specimens treated in the paper were deposited in Department of Biology, Shanghai Normal University, P. R. China.

\section{Taxonomy}

Brathinus satoi Kishimoto \& Shimada, 2003

http://species-id.net/wiki/Brathinus_satoi

Figs 1-9

Material examined. China: Zhejiang: 19 , Longwangshan, $1200 \mathrm{~m}, 25 . I V .2004$,

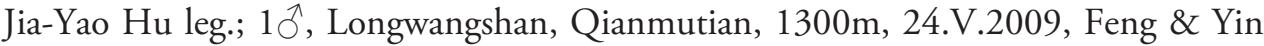
leg.; $11 \delta^{\widehat{ }} \mathrm{o}^{5} 5$ 우, same locality, $1250 \mathrm{~m}-1450 \mathrm{~m}, 30^{\circ} 23^{\prime} \mathrm{N}, 119^{\circ} 26^{\prime} \mathrm{E}, 14 . V .2013$, Yu, Li, Zheng, Chen, Pan, Hu \& Tang leg.; 10̂, same locality, 1050-1200m, near $30^{\circ} 24^{\prime} 28^{\prime \prime N}, 119^{\circ} 26^{\prime} 25^{\prime \prime E}, 15 . V .2013$, Chen \& Pan leg.

Distribution. China (Sichuan, Zhejiang).

Comments. This species can be easily recognized by rugose punctation along supraorbital furrows (Fig. 3) and several additional characters: antennae reddish brown with antennomeres 9 and 10 pale and antennomere 11 blackish; each elytron (Fig. 4) with a large yellowish mark extending from the elytral center to a broad yellowish band along the lateral margin, anterad and posterad from the midpoint; profemur and metafemur with approximately half of the apical portion darker, mesofemur with apical portion slightly darker (Figs 1,2); median lobe of aedeagus with a sclerotized 


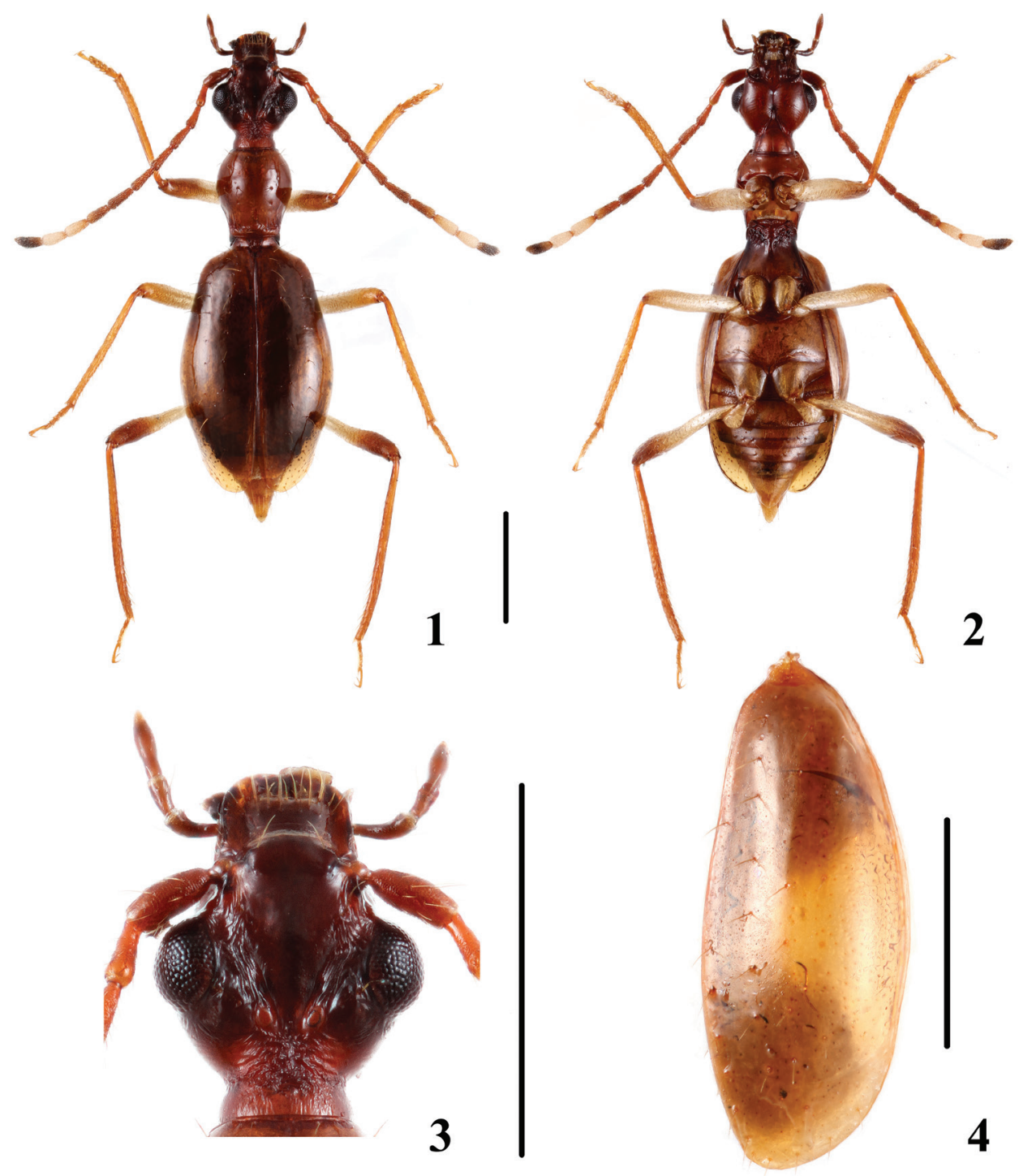

Figures I-4. Brathinus satoi. I, 2 adult habitus, (1) dorsal, (2 ventral $\mathbf{3}$ head, dorsal $\mathbf{4}$ right elytron, dorsal. Scale lines $=1 \mathrm{~mm}$.

apical portion which is delimited basally by a curved margin (Figs 5-7). In immature specimens, however, the elytral coloration is hardly discernible.

Biological notes. Most specimens were collected by sifting leaf litter along a stream in the forest, sometimes even along the bed of temporary brooks (Fig. 8). Two individuals were observed actively moving on the underside of a wet log lying close to a tiny stream (Fig. 9). In the past ten years, many collecting trips were made to Longwanshan 

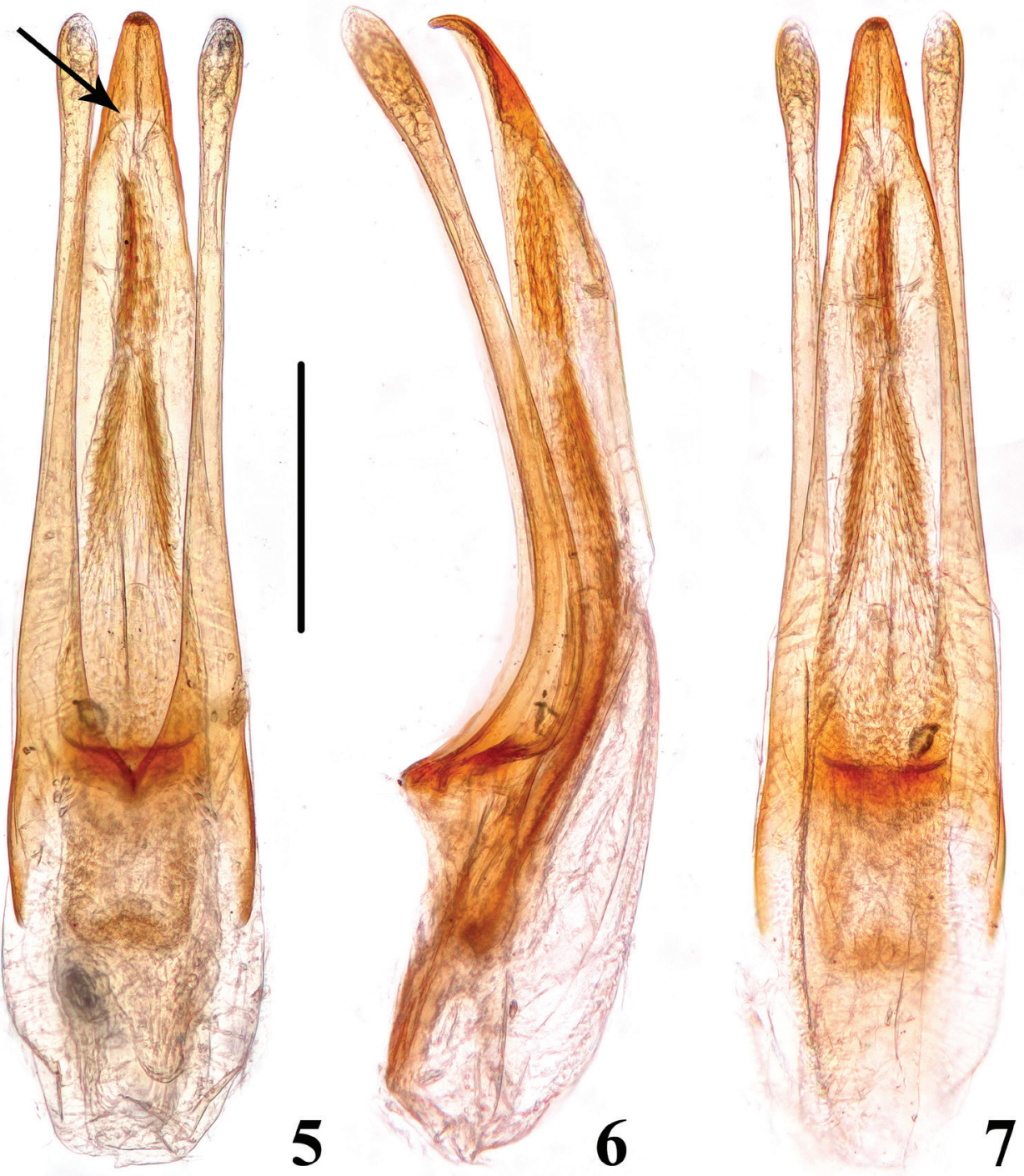

Figures 5-7. Aedeagus of Brathinus satoi. 5 ventral 6 lateral 7 dorsal. Scale line $=0.25 \mathrm{~mm}$.

from the middle of April to the beginning of October, covering all altitudes of the area in each trip $(300-1500 \mathrm{~m})$, and the collections show that the activity period of the adults is during late April through May at the higher altitudes of the area, above $1000 \mathrm{~m}$.

\section{Acknowledgements}

We thank Dr. Margaret Thayer (USA) for significantly improving the manuscript and all the collectors mentioned in the paper. The research was supported by the National 


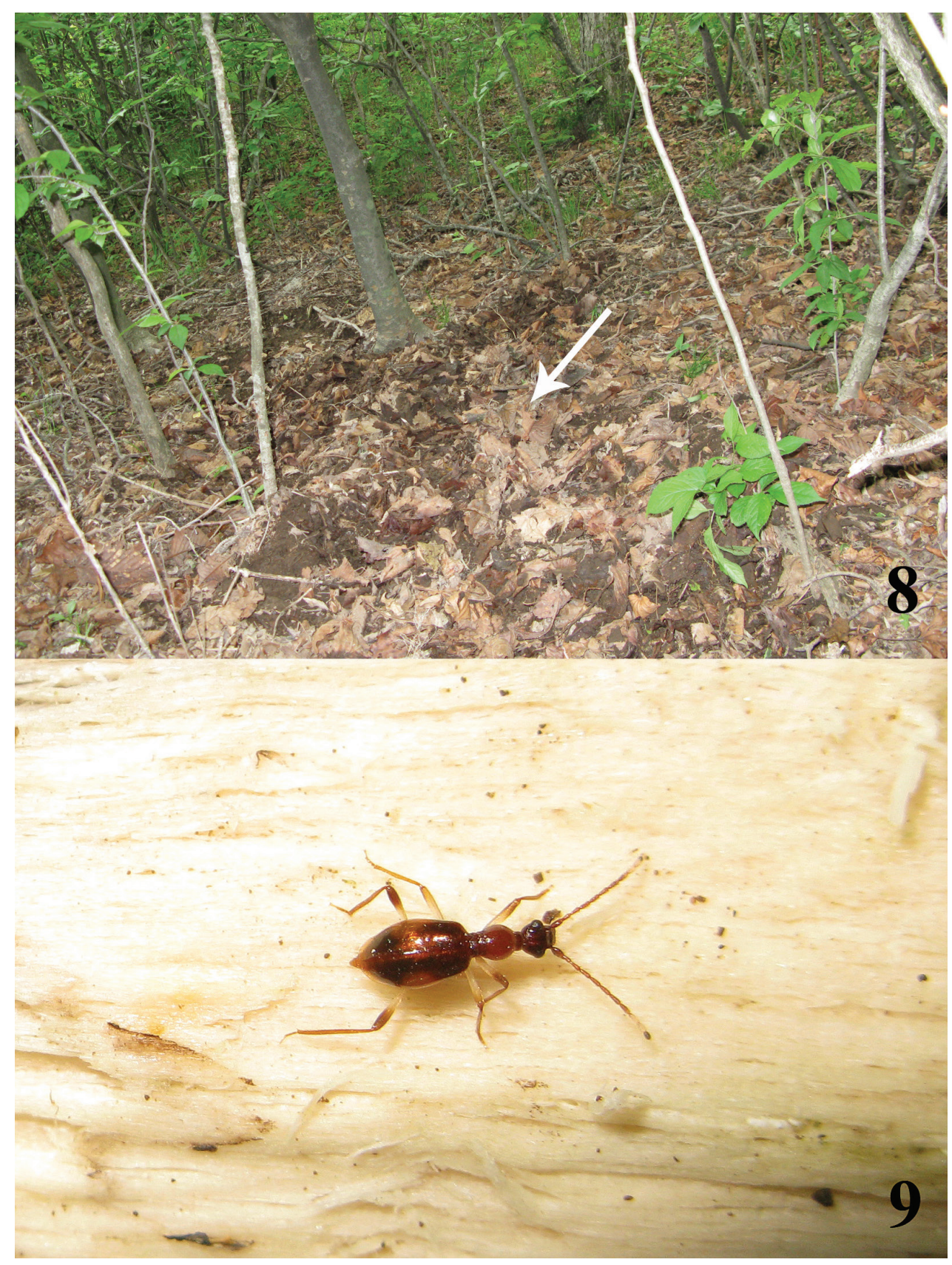

Figures 8, 9. 8 Habitat in Longwangshan 9 Brathinus satoi moving on wet log.

Natural Science Foundation of China (No. 31101659 and No. 31172134), the National Natural Science Foundation of Shanghai (No. 10ZR1421600) and the Innovation Program of Shanghai Municipal Education Commission (No. 12YZ077). 


\section{References}

Arnett RH (1963) The beetles of the United States (a manual for identification). Catholic University of America Press, Washington, D.C., xi + 1112 pp.

Crowson RA (1955) The natural classification of the families of Coleoptera. Nathaniel Lloyd, London, 187 pp. [seen as 1967 reprint, E. W. Classey, Hampton, with Addenda reprinted from Entomologist's Monthly Magazine 103: 209-214].

Hammond PM (1971) The systematic position of Brathinus LeConte and Camioleum Lewis (Coleoptera: Staphylinidae). Journal of Entomology (B) 40: 63-70.

Hubbard HG (1894) Note on Brathinus. Proceedings of the Entomological Society of Washington 3(1): 10-12.

Kishimoto T, Shimada T (2003) Brathinus satoi sp. nov. (Coleoptera, Staphylinidae), a new species of peculiar omaliine beetle from Sichuan, China. Special Bulletin of the Japanese Society of Coleopterology (6): 145-149.

LeConte JL (1852) Synopsis of the Scydmaenidae of the United States. Proceedings of the Academy of Natural Sciences of Philadelphia 6: 149-157.

LeConte JL (1861) Classification of the Coleoptera of North America. Part I. Smithsonian Miscellaneous Collections 3: $\mathrm{i}-\mathrm{xxv}+1-208$.

Lewis G (1886) A new species of Brathinus (Silphidae). The Entomologist's Monthly Magazine 23: 85.

Thayer MK (1985) The larva of Brathinus nitidus LeConte and the systematic position of the genus (Coleoptera: Staphylinidae). Coleopterists Bulletin 39 (2): 174-184.

Watanabe Y (1990) A taxonomic study on the subfamily Omaliinae from Japan (Coleoptera, Staphylinidae). Memoirs of the Tokyo University of Agriculture 31: 55-391.

Watanabe Y, Satô M (1981) A new Brathinus (Coleoptera, Staphylinidae) from Shikoku, Japan. Kontyû 49(4): 615-619. 